\title{
Equations for Plutonium and Americium-241 Decay Corrections
}

\author{
T. E. Sampson \\ J. L. Parker
}

\section{DISCLAIMER}

This report was prepared as an account of work sponsored by an agency of the United States Guvernment. Neither the United States Government nor any agency thereof, nor any of their employees, makes any warranty, express or implied, or assumes any legal liability or responsibility for the accuracy, completeness, or usefulsess of any information, apparatus, product, or process disclosed, or represents that its use would not infringe privately owned rights. Reference herein to any specific commercial product, process, or service by trade name, trademark, manufacturer, or otherwise does not necessarily constitute or imply its endorsement, recommendation, or favoring by the United States Government or any agency thereof. The views and opinions of authors expressed herein do not necessarily state or reflect those of the United States Goverrment or any agency thereof.

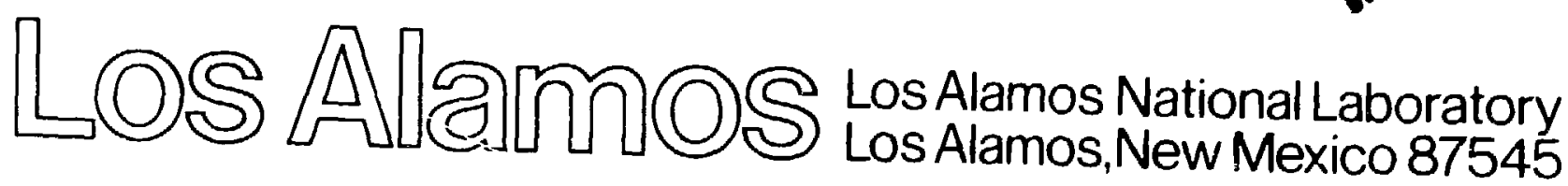




\section{CONTENTS}

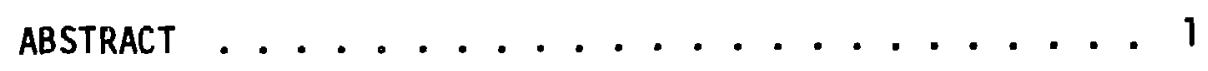

I. INTRDDUCTION .................. 1

II. STATEMENT OF THE PROBLEM . . . . . . . . . . . . . 2

III. NOTATION . . . . . . . . . . . . . 3

IV. DERIVATIONS ................... 4

V. SUMMARY ...................... 14

REFERENCE ....................... 16 


\title{
EQUATIONS FOR PLUTONIUM AND AMERICIUM-241 DECAY CORRECTIONS
}

by

T. E. Sampson and J. L. Parker

\begin{abstract}
We present derivations of equations used in various plutonium accountability measurements to correct for plutonium decay and 241 Am ingrowth and decay. The equations are formulated in terms of the most widely available variables and are derived witrout approximation.
\end{abstract}

\section{INTRODUCTION}

In accounting for plutonium one often must correct for the decay of the plutonium isotopes and the ingrowth and decay of the ${ }^{241}$ Am found in most plutonium.

These corrections involve the solucion of a rather simple differential equation, a process taught in all elementary courses on differential equations. The solution to this equation is also found in many textbooks describing radioactive decay. 1

In many cases the solutions found in the literature are not in the best form to be easily used in plutonium accountability problems. For instance, the equations are often solved for the number of atoms, whereas plutonium accounting is done on a mass basis. Equations are often expressed in terms of absolute mass, whereas ${ }^{241} \mathrm{Am}$ is measured relative to plutonium. Also, the textbook solutions usually simplify the initial conditions so that the initial ${ }^{241}$ Am content and the initial isotopic composition of the plutonium are given on the same day. This is seldom true in practice. Finaliy, the textbook solutions seldom show how the total plutonium mass varies with time. 
It is true that the approximations that are made to obtain these solutions can be adequate for many applications. However, with the widespread availability of computers, there should be no reason for not solving the problem in an exact manner and expressing the solution in terms of useful, observable variables.

In this report we will derive and present solutions for the variation of the plutonium isotopic fractions as a function of time, the ratio of ${ }^{241} \mathrm{Am}$ to plutonium as a function of time, and the variation of the total plutonium mass as a function of time. The solutions will be presented in termis of mass and mass fractions.

It is assumed that three measurements characterize the plutonium sample: (1) its isotopic composition, (2) its americium content, and (3) its plutonium mass. A11 three measurements are assumed to occur at arbitrary and different times. Using these three initial measurements, the three parameters can then be calculated at any arbitrary time--past, present, or future. All time differences are expressed explicitly in terms of the measurement time or date of the three initial measurements.

To apply these solutions, the following points should be ncted: First, "americium," in the context of these deviations, refers only to ${ }^{241}$ Am. Some plutonium samples, notably those of higher burnup, may contain ${ }^{243} \mathrm{Am}$. Whether "americium" content refers to total elemental americium or just to ${ }^{241}$ Am depends on the specific analytical techniques. Also, in the equations ${ }^{241} \mathrm{Am}$ is expressed as a ratio to total plutonium. Analytical results for ${ }^{241}$ Am are often expressed as ppm or a fraction of the sample mass rather than the plutonium mass. Finally, all plutonium isotopic measurements are expressed here in terms of mass fractions rather than atom fractions.

The user must be sure that the initial analytical results are properly interpreted before using them in the equations.

\section{STATEMENT OF THE PROBLEM}

Given values of the mass ratio ${ }^{241} \mathrm{Am} / \mathrm{Pu}$ at a known time and values of the plutonium isotopic mass fractions at a known (and generally different) time, compute the ${ }^{241} \mathrm{Am} / \mathrm{Pu}$ mass ratio at an arbitrary time $t$. 
III. NOTATION

Subscripts refer to isotopes:

$$
\begin{aligned}
& i=\text { plutonium isotopes, generally } i={ }^{238} \mathrm{Pu}, \ldots,{ }^{242} \mathrm{Pu}, \\
& 1={ }^{241} \mathrm{Pu}, \text { and } \\
& \mathrm{A}={ }^{241} \mathrm{Am} .
\end{aligned}
$$

Superscripts refer to times (absolute) or dates.

$I$ = values at time of plutonium isotopic determination,

$a$ = values at time of ${ }^{241} \underline{\mathrm{Am}} / \mathrm{Pu}$ ratio determination,

$m$ = values at time of plutonium mass determination,

$t^{I}=$ time of plutonium isotopic determination,

$\mathrm{t}^{\mathrm{a}}=\mathrm{time}$ of ${ }^{241} \mathrm{Anl} / \mathrm{Pu}$ mass ratio determination,

$t^{m}=$ time of plutonium mass determination,

$t=$ arbitrary time at which new values are to be calculatea,

$m$ = total plutonium mass in sample,

$m_{i}=$ mass of $i^{\text {th }}$ plutonium isotope in sample,

$R_{i}=m_{j} / m$, mass fraction of $i^{\text {th }}$ plutonium isotope relative to total plutonium,

$T_{j}=$ half-life of $i^{\text {th }}$ isotcpe,

$\lambda_{i}=\ell n 2 / T_{i}$, decay constant of $i^{\text {th }}$ isotope, 


$$
\begin{aligned}
& N_{i}=\text { number of atoms of isotope } i \text {, and } \\
& A_{i}=\text { atomic mass of isotope } i .
\end{aligned}
$$

\section{DERIVATIONS}

The amount of ${ }^{241}$ Am in a plutonium sample arises from its formation in the decay of ${ }^{241} \mathrm{Pu}$ and its destruction from its own decay. The differential equation governing the number of atoms of ${ }^{24 i}$ Am in a sample is

$$
\frac{d N_{A}}{d t}=-\lambda_{A} N_{A}+K_{1} \lambda_{1} N_{1}
$$

where $\mathrm{N}_{\mathrm{A}}=$ nu: $\rightarrow$ er of atoms of ${ }^{241} \mathrm{Am}$,

$$
\begin{aligned}
& N_{1}=\text { number of atoms of }{ }^{241} \mathrm{Pu} \text {, } \\
& \lambda_{A}=\text { decay constant of }{ }^{241} \mathrm{Am} \text {, } \\
& \lambda_{1}=\text { decay constant of }{ }^{241} \mathrm{Pu} \text {, } \\
& K_{1}=0.9999754 \text {, fraction of }{ }^{241} \mathrm{Pu} \text { decays that lead to }{ }^{241} \mathrm{Am} \text {, ac - } \\
& \text { counting for } 2.46 \cdot 10^{-3} \% \text { that decay to } 237 \mathrm{U} \text {. }
\end{aligned}
$$

Assume a solution of the form

$$
\begin{aligned}
& N_{A}(t)=B \exp \left(-\lambda_{A} t\right)+C \exp \left(-\lambda_{1} t\right) \text {, and } \\
& N_{1}(t)=N_{1}^{a} \exp \left[-\lambda_{1}\left(t-t^{a}\right)\right],
\end{aligned}
$$

with initial conditions that at $t=t^{a}$, 


$$
N_{A}\left(t^{a}\right)=N_{A}^{a} \text { and } N_{1}\left(t^{a}\right)=N_{1}^{a} \text {, }
$$

where $t^{a}=$ time that ${ }^{241} \mathrm{Am} / \mathrm{Pu}$ mass ratio was determined,

$$
\begin{aligned}
& N_{A}^{a}=\text { number of }{ }^{241} \mathrm{Am} \text { atoms present at time } t^{a} \text {, and } \\
& N_{1}^{a}=\text { number of }{ }^{241} \mathrm{Pu} \text { atoms present at time } t^{a} \text {. }
\end{aligned}
$$

This gives a solution for the number of atoms of ${ }^{241}$ Am at time $t$ as

$$
\begin{aligned}
N_{A}(t)= & N_{A}^{a} \exp \left[-\lambda_{A}\left(t-t^{a}\right)\right] \\
& +K_{1}\left(\frac{\lambda_{1}}{\lambda_{1}-\lambda_{A}}\right) N_{1}^{a}\left\{\exp \left[-\lambda_{A}\left(t-t^{a}\right)\right]-\exp \left[-\lambda_{1}\left(t-t^{a}\right)\right]\right\} .
\end{aligned}
$$

To make this equation more useful, convert atoms to mass noting that

$$
N=\frac{m \cdot N_{0}}{A},
$$

where $\mathrm{N}$ = number of atoms,

$$
\begin{aligned}
& m=\text { mass in grams, } \\
& A=\text { atomic mass (grams } / \text { mole }), \\
& N_{0}=6.022045 \cdot 10^{23} \text { atoms } / \mathrm{mole},
\end{aligned}
$$

and denoting

$$
A_{A}=\text { atomic mass of }{ }^{241} \mathrm{Am}, 241.056827 \text {, }
$$




$$
\begin{aligned}
& A_{1}=\text { atomic mass of }{ }^{241_{P u}, 241.056850,} \\
& m_{A}=\text { mass of }{ }^{241} 1_{A m} \text {, and } \\
& m_{1}=\text { mass of }{ }^{241} \mathrm{Pu} .
\end{aligned}
$$

This gives

$$
\begin{aligned}
& \begin{array}{l}
\frac{m_{A}(t)}{A_{A}}=\frac{m_{A}^{a}}{A_{A}} \\
\qquad \quad \exp \left[-\lambda_{A}\left(t-t^{a}\right)\right] \\
\left.\quad K_{1}\left(\frac{\lambda_{1}}{\lambda_{1}-\lambda_{A}}\right) \frac{m_{1}^{a}}{A_{1}} \exp \left[-\lambda_{A}\left(t-t^{a}\right)\right]-\exp \left[-\lambda_{1}\left(t-t^{a}\right)\right]\right\} .
\end{array} \\
& \text { Define } K_{2} \equiv \frac{A_{A}}{A_{1}}=0.999999905, \\
& \text { thus } K_{1} K_{2}=0.9999753,
\end{aligned}
$$

and we have for the mass of ${ }^{241} \mathrm{Am}$

$$
\begin{aligned}
m_{A}(t)= & m_{A}^{a} \exp \left[-\lambda_{A}\left(t-t^{a}\right)\right] \\
& +k_{1} k_{2}\left(\frac{\lambda_{1}}{\lambda_{1}-\lambda_{A}}\right) m_{1}^{a}\left\{\exp \left[-\lambda_{A}\left(t-t^{a}\right)\right]\right. \\
& \left.-\exp \left[-\lambda_{1}\left(t-t^{a}\right)\right]\right\} .
\end{aligned}
$$

6 
Equation (3) is expressed in terms of masses, whereas we desire the results to be expressed in terms of mass ratios to total plutonium because they are the measured observables.

So, let $i n=$ mass of plutcnium in the sample at the time indicated by $i$ ts superscript.

Define

$$
R_{A}(t)=\frac{m_{A}(t)}{m(t)} \text {, }
$$

and note that the liass decays just like the number of atoms; that is

$$
m_{i}(t)=m_{i}^{a} \exp \left[-\lambda{ }_{i}\left(t-t^{a}\right)\right]
$$

if there are $m_{i}^{a}$ grams of isotope $i$ present at time $t=\tau^{a}$.

The total plutonium mass is the sum of the masses of the individual plutonium isotopes, normally ${ }^{238} \mathrm{Pu},{ }^{239} \mathrm{Pu},{ }^{240} \mathrm{Pu}, 241 \mathrm{Pu}$, and ${ }^{242} \mathrm{Pu}$. Thus, the total plutonium mass present at time $t$ in terms of the isotopic masses present at time $t^{a}$ is

$$
m(t)=\sum_{i} m_{i}(t)=\sum_{i} m_{i}^{a} \exp \left[-\lambda_{i}\left(t-t^{a}\right)\right],
$$

where $i=$ all plutonium isotopes.

Divide Eq. (3) by Eq. (4) and, for compactness, denote the difference of the exponentials in Eq. (3) by \{\} in 


$$
R_{A}(t)=\frac{m_{A}^{a} \exp \left[-\lambda_{A}\left(t-t^{a}\right)\right]+k_{1} k_{2}\left(\frac{\lambda_{1}}{\lambda_{1}-\lambda_{A}}\right) m_{1}^{a}\{\}}{\sum_{i} m_{i}^{a} \exp \left[-\lambda_{i}\left(t-t^{a}\right)\right]}
$$

Divide the numerator and denominator by

$$
m^{a}=\sum_{i} m_{i}^{a}
$$

and define $R_{i} \equiv m_{j} / m$, the mass fractions relative to total plutonium.

We obtain

$$
R_{A}(t)=\frac{R_{A}^{a} \exp \left[-\lambda_{A}\left(t-t^{a}\right)\right]+k_{1} K_{2}\left(\frac{\lambda_{1}}{\lambda_{1}-\lambda_{A}}\right) R_{1}^{a}\{\}}{\sum_{i} R_{i}^{a} \exp \left[-\lambda_{i}\left(t-t^{a}\right)\right]} .
$$

In Eq. (6) we note the following:

$R_{A}^{a}$, generally known, is ${ }^{241} \mathrm{Am} / \mathrm{Pu}$ at the time of the ${ }^{241} \mathrm{Am}$ concentration measurement.

$R_{1}^{a}$ is not generally known. We do not assume that the plutonium isotopic fractions are measured at the same time as the americium.

$R_{j}^{a}$, likewise, is not generally known.

Thus, in Eq. (6) we need to obtain $R_{j}^{a}$ in terms of $R_{j}^{I}$.

To do this, let us derive the expression for the mass fractions at time $t$ in terms of those measured at time $t^{I}$ : 
$m_{i}^{I}=$ isotopic masses at time $t^{I}$,

$m^{I}=\sum_{\mathfrak{i}} m_{\mathfrak{i}}^{I}$, the total plutonium mass at $t^{I}$, and

$R_{\mathbf{i}}^{I}=\frac{m_{i}^{I}}{\sum m_{i}^{I}}$, the plutonium mass fractions at time $t^{I}$.

Decay the isotopic masses from time $t^{I}$ to time $t$, resulting in

$$
m_{i}(t)=m_{i}^{I} \exp \left[-\lambda_{i}\left(t-t^{I}\right)\right] .
$$

Then, mass fractions at time $t$ are

$$
R_{i}(t)=\frac{m_{j}(t)}{m(t)}=\frac{m_{i}^{I} \exp \left[-\lambda_{i}\left(t-t^{I}\right)\right]}{\sum_{i} m_{i}^{I} \exp \left[-\lambda_{i}\left(t-t^{I}\right)\right]} .
$$

Dividing both numerator and denominator by $\mathrm{m}^{\mathrm{I}}$ gives

$$
R_{i}(t)=\frac{R_{i}^{I} \exp \left[-\lambda_{j}\left(t-t^{I}\right)\right]}{\sum_{i} R_{i}^{I} \exp \left[-\lambda_{i}\left(t-t^{I}\right)\right]}
$$

where $i=$ all plutonium isotopes.

This equation shows how the plutonium mass fractions change with time. The denominator is a normalization factor because all the fractions must sum to unity. 
Now one can use the form of Eq. (7) to convert Eq. (6) to a form with observable parameters.

Substitute for $R_{i}^{a}$ in the denominator of Eq. (6),

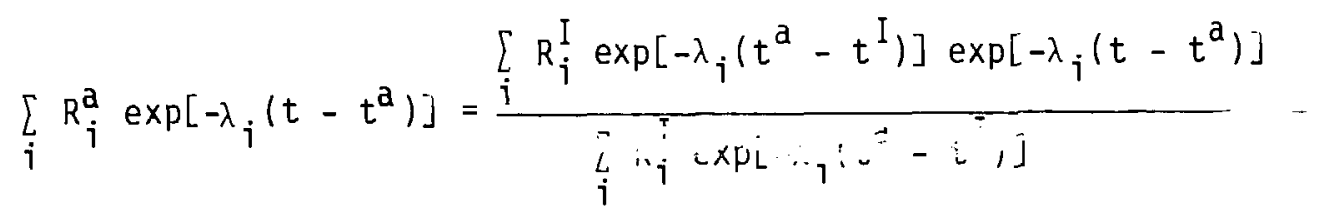

which simplifies to

$$
\frac{\sum_{i} R_{i}^{I} \exp \left[-\lambda_{i}\left(t-t^{I}\right)\right]}{\sum_{i} R_{i}^{I} \exp \left[-\lambda_{i}\left(t^{a}-t^{I}\right)\right]} \text {. }
$$

Define

$$
F(a) \equiv \sum_{i} R_{i}^{I} \exp \left[-\lambda_{i}\left(t^{a}-t^{I}\right)\right]
$$

and likewise

$$
F(t) \equiv \sum_{i} R_{i}^{I} \exp \left[-\lambda_{i}\left(t-t^{I}\right)\right] .
$$

Now Eq. (6) becomes

$$
R_{A}(t)=\frac{R_{A}^{a} \exp \left[-\lambda_{A}\left(t-t^{a}\right)\right]+k_{1} k_{2}\left(\frac{\lambda_{1}}{\lambda_{1}-\lambda_{A}}\right) k_{1}^{a}\{\}}{F(t) / F(a)} .
$$


Now use Eq. (7) again to put $R_{j}^{a}$ in terms of $R_{j}^{I}$ so that

$$
R_{1}^{a}=\frac{R_{1}^{I} \exp \left[-\lambda_{1}\left(t^{a}-t^{I}\right)\right]}{\sum_{i} R_{i}^{I} \exp \left[-\lambda_{i}\left(t^{a}-t^{I}\right)\right]}=\frac{R_{1}^{I} \exp \left[-\lambda_{1}\left(t^{a}-t^{I}\right)\right]}{F(a)},
$$

giving

$$
\begin{aligned}
R_{A}(t)= & \frac{F(a)}{F(t)} R_{A}^{a} \exp \left[-\lambda_{A}\left(t-t^{a}\right)\right. \\
& +\frac{K_{1} K_{2}}{F(t)}\left(\frac{\lambda_{1}}{\lambda_{1}-\lambda_{A}}\right) R_{1}^{I} \exp \left[-\lambda_{1}\left(t^{a}-t^{I}\right)\right]\{\} .
\end{aligned}
$$

Let us summarize this result in Eq. (8).

$$
\begin{aligned}
R_{A}(t)= & \frac{F(a)}{F(t)} R_{A}^{a} \exp \left[-\lambda_{A}\left(t-t^{a}\right)\right] \\
& +\frac{k_{1} k_{2}}{F(t)}\left(\frac{\lambda_{1}}{\lambda_{1}-\lambda_{A}}\right) R_{1}^{I} \exp \left[-\lambda_{1}\left(t^{a}-\dot{\tau}^{I}\right)\right] \\
& \cdot\left\{\exp \left[-\lambda_{A}\left(t-t^{a}\right)\right]-\exp \left[-\lambda_{1}\left(t-t^{a}\right)\right]\right\},
\end{aligned}
$$

where all variables are observables

$$
\begin{aligned}
& t=\text { time at which }{ }^{241} \mathrm{Am} / \mathrm{Pu} \text { ratio is desired, } \\
& \mathrm{t}^{\mathrm{a}}=\text { time of known }{ }^{241} \mathrm{Am} / \mathrm{Pu} \text { ratio, } \\
& \mathrm{t}^{\mathrm{I}}=\text { time of known plutonium isotopic values, }
\end{aligned}
$$




$$
\begin{aligned}
& \lambda_{A}=\text { decay constant of }{ }^{241} \mathrm{Am} \text {, } \\
& \lambda_{1}=\text { decay constant of }{ }^{241} \mathrm{Pu} \text {, } \\
& \lambda_{i}=\text { decay constant of piutonium isotope } i, i={ }^{238} \mathrm{Pu}_{1}, \ldots,{ }^{242} \mathrm{Pu} \text {, } \\
& \mathrm{R}_{\mathrm{A}}=\text { mass fraction of }{ }^{241} \mathrm{Am} \text { relative to plutonium, or }{ }^{241} \mathrm{Am} / \mathrm{Pu} \text {, } \\
& R_{A}^{a}=\text { mass fraction of }{ }^{241}{ }_{A m} \text { relative to plutonium, or }{ }^{241} \mathrm{Am} / \mathrm{Pu} \text { at time } \mathrm{t}^{\mathrm{a}} \text {, } \\
& R_{1}^{I}={ }^{241} \text { Pu mass fraction at time } t^{I} \text {, } \\
& \mathrm{K}_{1}=0.9999754 \text {, the }{ }^{241} \mathrm{Pu} \text { branching ratio to }{ }^{241} \mathrm{Arn} \text {, } \\
& K_{2}=0.999999905 \text {, the ratic of atomic musses }{ }^{241} \mathrm{Am} /{ }^{241} \mathrm{Pu} \text {, } \\
& R_{j}^{I}=\text { mass fraction of plutonium isotope } i \text { at time } t^{I} \text {, } \\
& F(a)=\sum_{i} R_{i}^{I} \exp \left[-\lambda_{i}\left(t^{a}-i^{I}\right)\right] \text {, and } \\
& F(t)=\sum_{i} R_{j}^{I} \exp \left[-\lambda_{i}\left(t-t^{I}\right)\right] .
\end{aligned}
$$

The last item to be derived is defined by the following problem:

Given that the mass of plutonium in a sample is known at time $t^{m}$, what is the mass at an arbitrary time $t$ where we assume that we know the isotopic composition at time $t^{I}$ ?

The mass of each isotope decays as

$$
m_{j}(t)=m_{j}^{m} \exp \left[-\lambda_{j}\left(t-t^{m}\right)\right] .
$$


The total mass is

$$
m(t)=\sum_{i} m_{i}(t)=\sum_{i} m_{i}^{m} \exp \left[-\lambda_{i}\left(t-t^{m}\right)\right] .
$$

Multiply and divide the right hand side by $m^{m}$ and note $m_{i}^{m} / m^{m}=R_{i}^{m}$ so that

$$
m(t)=m^{m} \sum_{i} R_{i}^{m} \exp \left[-\lambda_{i}\left(t-t^{m}\right)\right]
$$

From Eq. (7)

$$
R_{i}\left(t^{m}\right)=R_{i}^{m}=\frac{k_{i}^{I} \exp \left[-\lambda_{i}\left(t^{m}-t^{I}\right)\right]}{\sum_{i} R_{i}^{I} \exp \left[-\lambda_{i}\left(t^{m}-i^{I}\right)\right]} .
$$

Thus ,

$$
m(t)=m^{m} \frac{\left[R_{i}^{I} \exp \left[-\lambda_{i}\left(t^{m}-t^{I}\right)\right] \exp \left[-\lambda_{i}\left(t-t^{m}\right)\right]\right.}{\sum_{i} R_{i}^{I} \exp \left[-\lambda_{i}\left(t^{m}-t^{I}\right)\right]}
$$

giving

$$
m(t)=\frac{m^{m} \sum_{i} R_{i}^{I} \exp \left[-\lambda_{i}\left(t-t^{I}\right)\right]}{F(m)},
$$


where

$$
F(m)=\sum_{i} R_{i}^{I} \exp \left[-\lambda_{i}\left(t^{i \prime \prime}-t^{I}\right)\right]
$$

\section{SUMMARY}

We have derived expressions for three time-depsindent quantities used in plutonium accountability calculations:

1. The change in the isotopic composition as a function of time,

2. The ${ }^{241} \mathrm{Am} / \mathrm{Pu}$ ratio as a function of time, and

3. The plutonium mass as a function of time.

All three parameters are expressed in terms of the variables that are most commonly available to the user, the time of an initial plutonium isotopic composition measurement, the time of an ${ }^{241} \mathrm{Am} / \mathrm{Pu}$ ratio measurement, and the time of a sample plutonium mass measuremeni. All these times may be different. Because mass is used in accountability calculations, all ratios are expressed on a mass (not atom) basis.

It is inportant that the user assure that the input to these equations is in the proper units.

The results are summarized below.

Plutonium mass fraction at time $t i_{i l}$ terms of those measured at time $t^{I}$, from Eq. (7), is

$$
R_{i}(t)=\frac{R_{i}^{I} \exp \left[-\lambda_{i}\left(t-t^{I}\right)\right]}{F(t)} .
$$

The ${ }^{241}$ Am mass fraction relative to plutonium at time $t$, from Eq. (8), is 


$$
\begin{aligned}
R_{A}(t)= & \frac{F(a)}{F(t)} R_{A}^{a} \exp \left[-\lambda_{A}\left(t-t^{\hat{a}}\right)\right] \\
& +\frac{k_{1} K_{2}}{F(t)}\left(\frac{\lambda_{1}}{\lambda_{1}-\lambda_{A}}\right) R_{1}^{I} \exp \left[-\lambda_{1}\left(t^{a}-t^{I}\right)\right] \\
& \cdot\left\{\exp \left[-\lambda_{A}\left(t-t^{a}\right)\right]-\exp \left[-\lambda_{1}\left(t-t^{a}\right)\right] / .\right.
\end{aligned}
$$

The sample plutoniumi mass at time $t$ in terms of its known value at time $t^{\text {in }}$, from Eq. (9), is

$$
m(t)=\frac{m^{m} \sum_{i} R_{i}^{I} \exp \left[-\lambda_{i}\left(t-t^{I}\right)\right]}{F(m)} .
$$

Also summarizing the notation are the definitions

$t=$ arbitrary time or date at which new values are to be calculated, $t^{I}=$ time or date of initial pistonium isotopic composition determination,

$t^{a}=$ time or date of initial ${ }^{241}$ Am/Pu mass ratio determination,

$t^{m}=$ time or date of initial plutonium sample mass determination,

$m=$ plutonium mass in sample,

$m_{i}=$ mass of $i^{\text {th }}$ isotope in sample,

$R_{j}=m_{j} / m$, or mass fraction of $i^{\text {th }}$ isotope relative to plutonium,

$R_{j}^{1}=$ mass fraction of plutonium isotope $i$ at time $t^{I}$, 
$R_{A}=$ mass fraction of ${ }^{241}$ Am relative to plutonium,

$R_{A}^{a}=$ mass fraction of ${ }^{241}$ Am relative to plutonium at time $t^{a}$,

$T_{j}=$ half-life of $i^{\text {th }}$ isotope,

$\lambda_{i}=\ln 2 / T_{i}$, or decay constant of $i^{\text {th }}$ isotope,

$\lambda_{A}=$ decay constant of ${ }^{241} \mathrm{Am}$,

$\lambda_{1}=$ decay constant of ${ }^{241} \mathrm{Pu}$,

$K_{1}=0.9999754,{ }^{241} \mathrm{Pu}$ branching ratio to ${ }^{241} \mathrm{Am}$,

$K_{2}=0.999999905$, atomic mass ratio for ${ }^{241} \mathrm{Am} /{ }^{241} \mathrm{Pu}$,

$F(t)=\sum_{j} R_{i}^{I} \exp \left[-\lambda_{i}\left(t-t^{I}\right)\right]$, in which $i=$ plutonium isotopes,

$F(a)=\sum_{\dot{j}} R_{i}^{I} \exp \left[-\lambda_{i}\left(t^{a}-t^{I}\right)\right]$, in which $i=$ plutonium isotopes, and

$F(m)=\sum_{i} R_{i}^{I} \exp \left[-\lambda{ }_{i}\left(t^{m}-t^{I}\right)\right]$, in which $i=$ plutoniurn isotopes.

\section{REFERENCE}

1. Robley D. Evans, The Atomic Nucleus (McGraw-Hill Book Company, Inc., New York, 1955), pp. 470-510. 